\title{
Radiation-Induced Lymphopenia Beyond the COVID-19 Pandemic
}

\author{
Giuseppe Carlo lorio ${ }^{1 *}$, Umberto Ricardi ${ }^{1}$ and Alan Dal Pra ${ }^{2}$ \\ 1 Department of Oncology, Radiation Oncology, University of Turin, Turin, Italy, ${ }^{2}$ Department of Radiation Oncology, \\ University of Miami Miller School of Medicine, Miami, FL, United States
}

Keywords: COVID-19, lymphopenia, cancer, radiotherapy, toxicity

\section{OPEN ACCESS}

Edited by:

Ira Ida Skvortsova,

Innsbruck Medical University, Austria

Reviewed by:

Valentina Lancellotta,

Catholic University of the Sacred

Heart, Italy

Niccolo Giaj Levra,

Sacro Cuore Don Calabria

Hospital, Italy

*Correspondence:

Giuseppe Carlo lorio

giuseppecarlo.iorio@libero.it

Specialty section:

This article was submitted to

Radiation Oncology,

a section of the journal

Frontiers in Oncology

Received: 14 October 2020

Accepted: 22 October 2020

Published: 18 November 2020

Citation:

lorio GC, Ricardi U and Dal Pra A

(2020) Radiation-Induced

Lymphopenia Beyond the

COVID-19 Pandemic.

Front. Oncol. 10:617302.

doi: 10.3389/fonc.2020.617302
The novel human Coronavirus (SARS-CoV-2) pandemic started in late 2019 has killed more than 1 million people worldwide (1). The fatality rate has been linked with a hyperinflammation state dependent of human interleukin-6 levels and a cytokine-release syndrome (2). This proinflammatory micro-environment can induce lymphocyte-deficiency via apoptosis, impairing immune-homeostasis, and inflammatory-response (3). Indeed, lymphopenia has emerged as a major predictor of severe COVID-19 (3). A lymphocyte count $<1.5 \times 10^{9} / \mathrm{L}$ has been associated with a three-fold increased risk of severe COVID-19 (4). Noteworthy, lymphocytes express AngiotensinConverting Enzyme 2 (ACE2) receptor which is exploited by the SARS-CoV-2 to enter host targetcells, thus representing a possible virus direct target with a subsequent, potentially lethal, lymphatic organs attack (3).

Cancer treatments can often suppress reservoir lymphoid organs causing lymphopenia, which is associated with an increased risk of opportunistic infections and worse oncologic outcomes due to the lymphocytes essential role within the anti-tumor immune response (5). Although chemotherapy (CT) is often the main trigger of hematologic toxicity (HT), radiotherapy is also a contributing factor for impairment of hematologic cell lines $(6,7)$. Lymphocytes are extremely radiosensitive and show exponential decline early and throughout irradiation (8). The lethal dose required to reduce the surviving fraction of lymphocytes by $50 \%$ (LD50) is only $1.5 \mathrm{~Gy}$, and by $90 \%$ (LD90), 3 Gy (9). Radiation-induced lymphopenia (RIL) has been reported to negatively affect prognosis in several neoplasms including non-small cell lung cancer (NSCLC), glioblastoma, pancreatic cancer, esophageal cancer, and head and neck cancers (10-19). Lee et al. evaluated RIL in a cohort of 497 locally advanced pancreatic cancer patients treated with chemoradiation (10). Large radiotherapy volumes and low baseline lymphocyte count predicted for acute severe lymphopenia development and recovery. The authors highlighted the importance of severe acute lymphopenia as it was associated with both poorer overall survival (OS) and progression-free survival (PFS) (10). For NSCLC, Jin et al. considered the immune system as an organ-at-risk in the radiotherapy planning. The estimated dose of radiation to circulating immune cells (EDRIC) model was developed, and a higher EDRIC was associated with not only a greater risk of grade 3 or worse lymphopenia but also with poorer oncological outcomes (tumor progression and cancer deaths) within the RTOG-0617 study $(12,13)$. Tang et al. reported a significant association between lung low-dose exposure (V1-V5), involving the pulmonary vasculature circulating lymphocytes, and lymphopenia degree (14). For esophageal cancers, So et al. found that a low lymphocyte nadir was predictor for OS (hazard ratio $=0.63 ; \mathrm{p}<0.001$ ) (16). The authors highlighted a significant correlation between radiation dose to circulating immune cells and the lymphocytes nadir (16). 
Lymphopenia has been previously correlated with vertebral bone marrow (BM) radiation volumes in esophageal cancers (17).

This is in line with data reported for patients undergoing pelvic nodal radiotherapy (PNRT), as BM dose-volume parameters have been associated with the onset of HT, particularly leukopenia $(6,7$, 20). Although BM represents only part of the pelvic reservoir lymphoid organs together with lymph nodes, circulating lymphocytes, and gut mucosa, radiation-induced BM suppression is a predictor of leukopenia and lymphopenia $(6,7,20,21) . \mathrm{BM}$ stem cells are exquisitely radiosensitive and, in the average adult population, half of the hematopoietically active $\mathrm{BM}(\mathrm{aBM})$ is located within pelvic bones and lumbar vertebrae $(6,7,20,21)$.

Regarding dosimetric parameters predictive of HT, data from cervical cancer suggest that volumes receiving low-dose are important, e.g., pelvic BM V10 < 90\%-95\% and V $20<76 \%-80 \%$ to avoid grade 2-3 HT, especially leukopenia $(6,22)$. In the RTOG0418, which included cervical and endometrial cancer patients, BM V40 and median BM dose were linked with higher rates of grade 2 or worse HT (23). Techniques to spare BM, like the employment of PET-guided aBM sparing, have resulted in a significant decrease in HT, particularly grade 3 or worse neutropenia (24).

Similar to cervical cancer, an association between larger volumes receiving low-doses and HT emerged from anal cancer studies $(25,26)$. Bazan et al. also highlighted the role of the mean pelvic BM dose as a useful toxicity predictor for anal cancer patients, recommending a mean dose at $<22.5-25$ Gy (25), and supporting the hypothesis of considering the pelvic BM as a parallel organ when predicting $\operatorname{HT}(25,27)$.

Several studies addressed radiation-induced BM suppression in rectal cancer patients undergoing PNRT. In a series of 120 rectal cancer patients treated with neoadjuvant pelvic radiotherapy and concurrent 5-fluorouracil-based CT, Yang et al. found that coxal BM V45 ( $\mathrm{p}=0.03)$ and sacral BM V45 $(\mathrm{p}=0.03)$ were associated with a lower leukocyte count and lower absolute neutrophil count ratio at nadir, respectively. Of interest, among all HTs, lymphopenia occurred most frequently: grade 2 lymphopenia was observed in $97.5 \%$ of patients while grade 3 in $56.7 \%$ (8).

In a mixed population of different pelvic cancers, including rectal, cervical, anal, vaginal, and bladder cancer patients, McGuire et al. reported lymphopenia as the most common recorded toxicity (28).

Chronically lower lymphocytes counts (at 1-2 years after treatment) have been observed in prostate cancer patients

\section{REFERENCES}

1. Johns Hopkins Coronavirus Resource Center. COVID-19 Map. Available at: https://coronavirus.jhu.edu/map.html (Accessed October 14, 2020).

2. Metha P, McAuley DF, Brown M, Sanchez E, Tattersall RS, Manson JJ, et al. COVID-19: consider cytokine storm syndromes and immunosuppression. Lancet (2020) 395:1033-4. doi: 10.1016/S0140-6736(20)30628-0

3. Tan L, Wang Q, Zhang D, Ding J, Huang Q, Tang YQ, et al. Lymphopenia predicts disease severity of COVID-19: a descriptive and predictive study. Signal Transduct Target Ther (2020) 5:33. doi: 10.1038/s41392-020-0148-4

4. Zhao Q, Meng M, Kumar R, Wu Y, Huang J, Deng Y, et al. Lymphopenia is associated with severe coronavirus disease 2019 (COVID-19) infections: A systemic review and meta-analysis. Int J Infect Dis (2020) 96:131-5. doi: $10.1016 /$ j.ijid.2020.04.086 undergoing PNRT $(20,29)$. In this regard, Sini et al. highlighted a higher risk of both acute and late lymphopenia with BM mediumhigh doses exposure ( $\geq 40 \mathrm{~Gy}$ ) (20).

Accordingly, data of an Italian multicentric study with 406 prostate cancer patients treated with PNRT showed an association between large nodal volumes ( $>900 \mathrm{cc}$ ) and acute grade 3 or worse and late grade 2 or worse lymphopenia (lasting at least 1 year) (29). Thus, prostate cancer radiotherapy is a particularly interesting scenario for radiation-induced HT studies, given the increasing use of larger RT volumes to the pelvis.

In times of pandemic, radiation oncologists should be cautious about utilizing large elective radiation volumes, particularly when the benefit is uncertain, to avoid suppression of reservoir lymphoid organs (30). Perhaps short-fractionation schedules, widely preconized during this outbreak (30), could have less impact on hematologic counts, particularly extremehypofractionation with steep dose-gradients (11). The low entrance-dose and sharp fall-off of proton therapy have been shown to decrease the RIL risk and severity by minimizing unintended irradiation to circulating immune cells (31). Proton therapy offers dosimetric advantages in BM sparing when delivering PNRT as compared to intensity-modulated radiotherapy and volumetric arc therapy $(32,33)$. Therefore, stereotactic body radiotherapy (SBRT) and proton therapy may represent promising approaches for "lymphocyte sparing radiotherapy" $(21,31)$. Additionally, brachytherapy, given the favorable dose distribution to normal tissues, should also be kept in mind for more effective "immune-sparing" radiotherapy approaches (34-37).

Finally, although there is important evidence addressing radiation-induced HT and lymphopenia, there is still a great deal of uncertainty on its long-term oncological implications. In light of the importance of a normal lymphocyte count during the COVID-19 pandemic, we face an unprecedented opportunity for further elucidation of the impact of RIL and "lymphocytesparing" strategies.

\section{AUTHOR CONTRIBUTIONS}

All authors listed have made a substantial, direct, and intellectual contribution to the work, and approved it for publication.
5. Tanriverdi O. Lymphopenia that may develop in patients treated with temozolomide and immune control check-point inhibitor may be a high risk for mortality during the COVID-19 outbreak. Med Oncol (2020) 37:51 doi: 10.1007/s12032-020-01376-8

6. Mell LK, Kochanski JD, Roeske JC, Haslam JJ, Mehta N, Yamada SD, et al. Dosimetric predictors of acute hematologic toxicity in cervical cancer patients treated with concurrent cisplatin and intensity-modulated pelvic radiotherapy. Int J Radiat Oncol Biol Phys (2006) 66:1356-65. doi: 10.1016/j.ijrobp.2006.03.018

7. Franco P, Arcadipane F, Ragona R, Lesca A, Gallio E, Mistrangelo M, et al. Dose to specific subregions of pelvic bone marrow defined with FDG-PET as a predictor of hematologic nadirs during concomitant chemoradiation in anal cancer patients. Med Oncol (2016) 33:72. doi: 10.1007/s12032-016-0789-x

8. Yang TJ, Oh JH, Apte A, Son CH, Deasy JO, Goodman KA. Clinical and dosimetric predictors of acute hematologic toxicity in rectal cancer patients 
undergoing chemoradiotherapy. Radiother Oncol (2014) 113:29-34. doi: 10.1016/j.radonc.2014.09.002

9. Nakamura N, Kusunoki Y, Akiyama M. Radiosensitivity of CD4 or CD8 positive human T-lymphocytes by an in vitro colony formation assay. Radiat Res (1990) 123:224-7. doi: 10.2307/3577549

10. Lee BM, Byun HK, Seong J. Significance of lymphocyte recovery from treatment-related lymphopenia in locally advanced pancreatic cancer. Radiother Oncol (2020) 151:82-7. doi: 10.1016/j.radonc.2020.07.026

11. Wild AT, Herman JM, Dholakia AS, Moningi S, Lu Y, Rosati LM, et al. Lymphocyte-Sparing Effect of Stereotactic Body Radiation Therapy in Patients With Unresectable Pancreatic Cancer. Int J Radiat Oncol Biol Phys (2016) 94:571-9. doi: 10.1016/j.ijrobp.2015.11.026

12. Jin JY, Hu C, Xiao Y, Zhang H, Ellsworth S, Schild SE, et al. Higher Radiation Dose to Immune System is Correlated With Poorer Survival in Patients With Stage III Non-small Cell Lung Cancer: A Secondary Study of a Phase 3 Cooperative Group Trial (NRG Oncology RTOG 0617). Int J Radiat Oncol Biol Phys (2017) 99:S151-2. doi: 10.1016/J.IJROBP.2017.06.35

13. Ladbury CJ, Rusthoven CG, Camidge DR, Kavanagh BD, Nath SK. Impact of Radiation Dose to the Host Immune System on Tumor Control and Survival for Stage III Non-Small Cell Lung Cancer Treated with Definitive Radiation Therapy. Int J Radiat Oncol Biol Phys (2019) 105:346-55. doi: 10.1016/j.ijrobp.2019.05.064

14. Tang C, Liao Z, Gomez D, Levy L, Zhuang Y, Gebremichael RA, et al. Lymphopenia association with gross tumor volume and lung V5 and its effects on non-small cell lung cancer patient outcomes. Int J Radiat Oncol Biol Phys (2014) 89:1084-91. doi: 10.1016/j.ijrobp.2014.04.025

15. Abravan A, Faivre-Finn C, Kennedy J, McWilliam A, van Herk M. Radiotherapy-Related Lymphopenia Affects Overall Survival in Patients With Lung Cancer. J Thorac Oncol (2020) 15:1624-35. doi: 10.1016/ j.jtho.2020.06.008

16. So TH, Chan SK, Chan WL, Choi H, Chiang CL, Lee V, et al. Lymphopenia and Radiation Dose to Circulating Lymphocytes With Neoadjuvant Chemoradiation in Esophageal Squamous Cell Carcinoma. Adv Radiat Oncol (2020) 5:880-8. doi: 10.1016/j.adro.2020.03.021

17. Newman NB, Anderson JL, Sherry AD, Osmundson EC. Dosimetric analysis of lymphopenia during chemoradiotherapy for esophageal cancer. $J$ Thorac Dis (2020) 12:2395-405. doi: 10.21037/jtd.2020.03.93

18. Yovino S, Kleinberg L, Grossman SA, Narayanan M, Ford E. The etiology of treatment-related lymphopenia in patients with malignant gliomas: modeling radiation dose to circulating lymphocytes explains clinical observations and suggests methods of modifying the impact of radiation on immune cells. Cancer Invest (2013) 31:140-4. doi: 10.3109/07357907.2012.762780

19. Campian JL, Sarai G, Ye X, Marur S, Grossman SA. Association between severe treatment-related lymphopenia and progression-free survival in patients with newly diagnosed squamous cell head and neck cancer. Head Neck (2014) 36:1747-53. doi: 10.1002/hed.23535

20. Sini C, Fiorino C, Perna L, Noris Chiorda B, Deantoni CL, Bianchi M, et al. Dose-volume effects for pelvic bone marrow in predicting hematological toxicity in prostate cancer radiotherapy with pelvic node irradiation. Radiother Oncol (2016) 118:79-84. doi: 10.1016/j.radonc.2015.11.020

21. Lambin P, Lieverse RIY, Eckert F, Marcus D, Oberije C, van der Wiel AMA, et al. Lymphocyte-Sparing Radiotherapy: The Rationale for Protecting Lymphocyterich Organs When Combining Radiotherapy With Immunotherapy. Semin Radiat Oncol (2020) 30:187-93. doi: 10.1016/j.semradonc.2019.12.003

22. Rose BS, Aydogan B, Liang Y, Yeginer M, Hasselle MD, Dandekar V, et al. Normal tissue complication probability modeling of acute hematologic toxicity in cervical cancer patients treated with chemoradiotherapy. Int $J$ Radiat Oncol Biol Phys (2011) 79:800-7. doi: 10.1016/j.ijrobp.2009.11.010

23. Klopp AH, Moughan J, Portelance L, Miller BE, Salehpour MR, Hildebrandt E, et al. Hematologic toxicity in RTOG 0418: a phase 2 study of postoperative IMRT for gynecologic cancer. Int J Radiat Oncol Biol Phys (2013) 86:83-90. doi: 10.1016/j.ijrobp.2013.01.017

24. Mell LK, Sirák I, Wei L, Tarnawski R, Mahantshetty U, Yashar CM, et al. Bone Marrow-sparing Intensity Modulated Radiation Therapy With Concurrent Cisplatin For Stage IB-IVA Cervical Cancer: An International Multicenter
Phase II Clinical Trial (INTERTECC-2). Int J Radiat Oncol Biol Phys (2017) 97:536-45. doi: 10.1016/j.ijrobp.2016.11.027

25. Bazan JG, Luxton G, Mok EC, Koong AC, Chang DT. Normal tissue complication probability modeling of acute hematologic toxicity in patients treated with intensity-modulated radiation therapy for squamous cell carcinoma of the anal canal. Int J Radiat Oncol Biol Phys (2012) 84:700-6. doi: 10.1016/j.jirobp.2011.12.072

26. Mell LK, Schomas DA, Salama JK, Devisetty K, Aydogan B, Miller RC, et al. Association between bone marrow dosimetric parameters and acute hematologic toxicity in anal cancer patients treated with concurrent chemotherapy and intensity-modulated radiotherapy. Int $J$ Radiat Oncol Biol Phys (2008) 70:1431-7. doi: 10.1016/j.ijrobp.2007.08.074

27. Cheng JC, Bazan JG, Wu JK, Koong AC, Chang DT. Lumbosacral spine and marrow cavity modeling of acute hematologic toxicity in patients treated with intensity modulated radiation therapy for squamous cell carcinoma of the anal canal. Pract Radiat Oncol (2014) 4:198-206. doi: 10.1016/j.prro.2013.07.011

28. McGuire SM, Bhatia SK, Sun W, Jacobson GM, Menda Y, Ponto LL, et al. Using [(18)F]Fluorothymidine Imaged With Positron Emission Tomography to Quantify and Reduce Hematologic Toxicity Due to Chemoradiation Therapy for Pelvic Cancer Patients. Int J Radiat Oncol Biol Phys (2016) 96:228-39. doi: 10.1016/j.ijrobp.2016.04.009

29. Rancati T, Sini C, Noris Chiorda B, Garibaldi E, Gabriele P, Munoz F, et al. PV-0627: Hematologic toxicity after whole-pelvis irradiation: results of a longitudinal observational study. Radiother Oncol (2018) 127:S332-3. doi: 10.1016/S0167-8140(18)30937-X

30. Joseph N, Choudhury A. Lymphocytopenia and Radiotherapy Treatment Volumes in the Time of COVID-19. Clin Oncol (R Coll Radiol) (2020) 32:4202. doi: 10.1016/j.clon.2020.04.011

31. Ellsworth SG. Field size effects on the risk and severity of treatment-induced lymphopenia in patients undergoing radiation therapy for solid tumors. $A d v$ Radiat Oncol (2018) 3:512-9. doi: 10.1016/j.adro.2018.08.014

32. Dinges E, Felderman N, McGuire S, Gross B, Bhatia S, Mott S, et al. Bone marrow sparing in intensity modulated proton therapy for cervical cancer: Efficacy and robustness under range and setup uncertainties. Radiother Oncol (2015) 115:373-8. doi: 10.1016/j.radonc.2015.05.005

33. Prasad RN, Freese C, Sudhoff M, Meier T, Lewis L, Mascia A, et al. Absolute volume of active bone marrow and total bone marrow spared in anal cancer patients using intensity modulated proton versus volumetric arc therapy. J Radiat Oncol (2018) 7:69-75. doi: 10.1007/s13566-017-0329-0

34. Grossman SA, Ellsworth S, Campian J, Wild AT, Herman JM, Laheru D, et al. Survival in Patients With Severe Lymphopenia Following Treatment With Radiation and Chemotherapy for Newly Diagnosed Solid Tumors. J Natl Compr Canc Netw. (2015) 13:1225-31. doi: 10.6004/jnccn.2015.0151

35. Yamazaki H, Yoshioka Y, Inoue T, Tanaka E, Nishikubo M, Sato T, et al. Changes in natural killer cell activity by external radiotherapy and/or brachytherapy. Oncol Rep (2002) 9:359-63. doi: 10.3892/or.9.2.359

36. Williams VM, Kahn JM, Harkenrider MM, Chino J, Chen J, Fang LC, et al. COVID-19 impact on timing of brachytherapy treatment and strategies for risk mitigation. Brachytherapy (2020) 19:401-11. doi: 10.1016/j.brachy. 2020.04.005

37. Zaorsky NG, Yu JB, McBride SM, Dess RT, Jackson WC, Mahal BA, et al. Prostate Cancer Radiation Therapy Recommendations in Response to COVID-19. Adv Radiat Oncol (2020) 5:659-65. doi: 10.1016/j.adro.2020.03.010

Conflict of Interest: The authors declare that the research was conducted in the absence of any commercial or financial relationships that could be construed as a potential conflict of interest.

Copyright $\odot 2020$ Iorio, Ricardi and Dal Pra. This is an open-access article distributed under the terms of the Creative Commons Attribution License (CC BY). The use, distribution or reproduction in other forums is permitted, provided the original author(s) and the copyright owner(s) are credited and that the original publication in this journal is cited, in accordance with accepted academic practice. No use, distribution or reproduction is permitted which does not comply with these terms. 